\section{Picturing Student Beliefs in Statistics}

\author{
Katrin Rolka, Duisburg (Germany)
}

Michael Bulmer, Brisbane (Australia)

\begin{abstract}
Statistical skills and statistical literacy have emerged as important areas in education. While it has a rich mathematical basis, successful understanding and application of statistics incorporates other types of knowledge. In a similar way, beliefs about statistics can be described using the same framework as beliefs about mathematics, but statistical beliefs bring other aspects as well. This article describes a project for investigating student beliefs in statistics through the creation of pictures of understanding. It presents a classification of statistical concepts and attitudes which are motivated by research in statistical literacy and then shows how these can be refined to be more reliably applied in practice.
\end{abstract}

Kurzreferat: „Statistical literacy“ hat sich mittlerweile zu einem wichtigen Forschungsthema in der Mathematikdidaktik entwickelt. Erfolgreiches Verstehen und Anwenden von Statistik geht allerdings über rein kognitive Aspekte des Lernprozesses hinaus. Es ist vielfach angemerkt worden, dass hierbei Beliefs eine nicht zu unterschätzende Bedeutung beigemessen werden muss. Gegenstand dieses Artikels ist eine Studie, in der Beliefs über Statistik von Studierenden mit Hilfe von Bildern untersucht werden. Auf der einen Seite zeigt sich, dass in den Bildern ähnliche Kategorien wie bei Beliefs über Mathematik zum Ausdruck kommen, auf der anderen Seite ergeben sich darüber hinaus weitere Aspekte zur Beschreibung von statistischen Beliefs. Diese Kategorien lassen sich auch vor dem Hintergrund der Forschungsergebnisse zu „statistical literacy“ interpretieren. Weiterführend wird gezeigt, wie diese Kategorien verfeinert werden können, um die Reliabilität zu erhöhen.

ZDM-Classification: C20, C30, D60

\section{Introduction}

In many parts of the world we are today living in an information society where the handling and interpretation of data is becoming increasingly important. Following this idea, basic statistical skills and statistical literacy build the foundation for many of our decisions (Niederman \& Boyum, 2003; Wallmann, 1993; Watson \& Callingham, 2003). Indeed, the NCTM standards state that "a knowledge of statistics is necessary if students are to become intelligent consumers who can make critical and informed decisions" (NCTM, 1989, p. 105). Recent dialogues on quantitative literacy or numeracy point in a similar direction (Steen, 1997).

At the same time, more and more researchers are taking into consideration the role of beliefs as a hidden variable in mathematics education (Leder, Pehkonen \& Törner, 2002). As many researchers point out, the learning and success in mathematics is influenced by student beliefs about mathematics and about themselves as mathematics learners (Schoenfeld, 1992). While there is substantial research on global beliefs about the nature of mathematics, teaching, and learning (Cooney \& Shealy, 1997; Lloyd, 1999), in this study we direct our attention to beliefs about statistics. The term statistical beliefs is used to reflect this related work on mathematical beliefs.

This focus on statistical beliefs seems to us to be fruitful since beliefs about statistics might remarkably differ, for example, from beliefs about algebra. Törner (2002) employs the term domain-specific beliefs to describe this phenomenon. Domain-specific beliefs are characterized as beliefs that are associated with a special field or domain of mathematics such as calculus, geometry, or statistics.

\section{Mathematical Beliefs}

Pajares (1992) describes beliefs as a "messy construct" and indeed beliefs have not yet been clearly defined in the literature. However, there is some consensus in that effect that mathematical beliefs are considered as personal philosophies or conceptions about the nature of mathematics as well as about teaching and learning mathematics (Thompson, 1992).

Dionne (1984) suggests that beliefs are composed of three basic components called the traditional perspective, the formalist perspective and the constructivist perspective. Similarly, Ernest (1991) describes three philosophies of mathematics called instrumentalist, Platonist and problem solving, while Törner and Grigutsch (1994) name the three components as toolbox aspect, system aspect and process aspect. All these different notions correspond more or less with each other.

In this work we employ these three components defined by Törner and Grigutsch (1994). In the "toolbox aspect", mathematics is seen as a set of rules, formulae, skills and procedures and mathematical activity means calculating as well as using rules, procedures and formulae. In the "system aspect", mathematics is characterized by logic, rigorous proofs, exact definitions and a precise mathematical language and doing mathematics consists of accurate proofs as well as of the use of a precise and rigorous language. In the "process aspect", mathematics is considered as a constructive process where relations between different notions and sentences play an important role. Here the mathematical activity involves creative steps, such as generating rules and formulae, thereby inventing or re-inventing the mathematics.

Besides these standard perspectives on mathematical beliefs, a further important component is the usefulness, or utility, of mathematics (Grigutsch, Raatz \& Törner, 1997). Utility is particularly relevant in statistics, where critical statistical literacy involes "questioning engagement with context” (Watson \& Callingham, 2003, p. 14), as discussed in the following section.

\section{Statistical Literacy}

Extending the use of "literacy" in the context of reading and writing, the term "mathematical literacy" was introduced within the scope of the PISA study. More 
recently, the term "statistical literacy" has also been adopted. Wallman (1993, p. 1) defines statistical literacy as follows:

Statistical Literacy is the ability to understand and critically evaluate statistical results that permeate our daily lives - coupled with the ability to appreciate the contributions that statistical thinking can make in public and private, professional and personal decisions.

Based on an analysis of student questionnaires, Watson and Callingham (2003) identified six levels of statistical literacy as a hierarchical construct. The lowest level is called "idiosyncratic", suggesting a "lack of engagement with their associated ideas and contexts" (p. 14). The middle level is "consistent", where students demonstrated an "appropriate but non-critical engagement with context" (p. 14). The highest level is called "critical mathematical", demanding "critical, questioning engagement with context, [...] showing appreciation of the need for uncertainty in making predictions, and interpreting subtle aspects of language” (p. 14).

\section{Methodology}

\subsection{Sample}

The subjects in the study were students undertaking the course "Analysis of Biological Data and Experiments", run at an Australian university in Semester 1, 2005 (from March to June). This is an applied course in statistics. It was taken by 184 students who were studying biological sciences, including genuine science students, but also students aiming to study medicine, dentistry, and other professions. A total of 164 students (89\%) submitted a picture as part of their assessment for the course.

\subsection{Study}

In the first two weeks of the course, students were asked to use an A4 sheet of paper to describe their views on statistics. Little had been covered in the lectures by this stage, with the pictures aiming to capture the initial understanding that students brought to the course. The wording on the instruction directed students to "take a blank sheet of A4 paper and draw, write, paint, doodle, or whatever" suits them best to express their views on statistics. Since the size of the paper used was A4, we refer to this as the "A4 Project". Bulmer and Rolka (2005) provide an overview of using pictures as a means for investigating beliefs in this way.

\subsection{Analysis}

The analysis was based on the three categories (A, B, and C2) that were identified in an earlier study of the same kind (Bulmer \& Rolka, 2005). We used these categories and tried to put all 164 pictures in one of the categories. Of course, some pictures were seen to express more than one aspect but it was usually possible to identify a dominant aspect for each picture.

As we independently classified the first 50 pictures, comparing classifications after every 10 pictures to check agreement and refine the aspects if required, we identified two new categories (C1 and $\mathbf{G}$ ). The remaining 114 pictures were then classified in a similar way but no changes were made to the aspect definitions.

For reasons of reliability, we had an assistant who was not involved in building the categories to classify the 164 pictures as well.

\section{Results}

The results of this study are the classifications of the pictures by the authors and by the assistant. In this section we describe the categories related to statistical literacy by giving an operational definition and an overview of typical features of each category, as well as an example picture for each category. We then present the results concerning the reliability of the classification process by comparing our results with those of the assistant. Finally, we give results on the emotional aspects which were expressed in some of the pictures, as well as some comments on the variety of artistic expression.

\subsection{Categories}

Based on discussions of the first 50 pictures, the five categories given in Table 1 were used to classify the role played by statistics in each of the pictures. The broad structure is hierarchical, reflecting certain levels in the hierarchical construct of Watson and Callingham (2003). The exception to this is category $\mathbf{G}$. This category had not been observed previously (Bulmer \& Rolka, 2005) but appeared a number of times in the new sample. Rather than expressing some aspect of statistics as an applied discipline of knowledge, these students expressed a metaphorical view of statistics.

\begin{tabular}{|c|c|}
\hline Aspect & Operational definitions \\
\hline A & $\begin{array}{l}\text { Shows "statistics" as a course that the student } \\
\text { is studying; statistics is just a thing. }\end{array}$ \\
\hline B & $\begin{array}{l}\text { Shows statistics as numbers and as a } \\
\text { collection of tools, such as different ways of } \\
\text { plotting data or calculating summary } \\
\text { statistics. }\end{array}$ \\
\hline C1 & $\begin{array}{l}\text { Shows a simple use of statistics; tools with a } \\
\text { context; no details about how it is used. }\end{array}$ \\
\hline $\mathrm{C} 2$ & $\begin{array}{l}\text { Explicitly shows statistics as a means of } \\
\text { - understanding a complex world } \\
\text { - understanding relationships } \\
\text { - presenting a unified picture of data. }\end{array}$ \\
\hline G & $\begin{array}{l}\text { Statistics as a world in itself: } \\
\text { - } \quad \text { statistical objects are part of the world } \\
\text { - } \quad \text { statistics as a game } \\
\text { - } \\
\text { surreal. }\end{array}$ \\
\hline
\end{tabular}

Table 1. Operational definitions of draft categories

Figure 1 shows an example picture classified as A. Figure 2 shows an example of $\mathbf{B}$, which also gives a strong example of a negative attitude. Figure 3 shows an example of C1. This is similar to the picture in Figure 2, showing statistics as a collection of tools, but here each example is given a context. The utility of statistics is more richly expressed in the picture in Figure 4, an 
example of category C2. Figure 5 shows a world which is filled with statistical elements, though not applied in any sense to modelling the world itself. This is an example of category G.

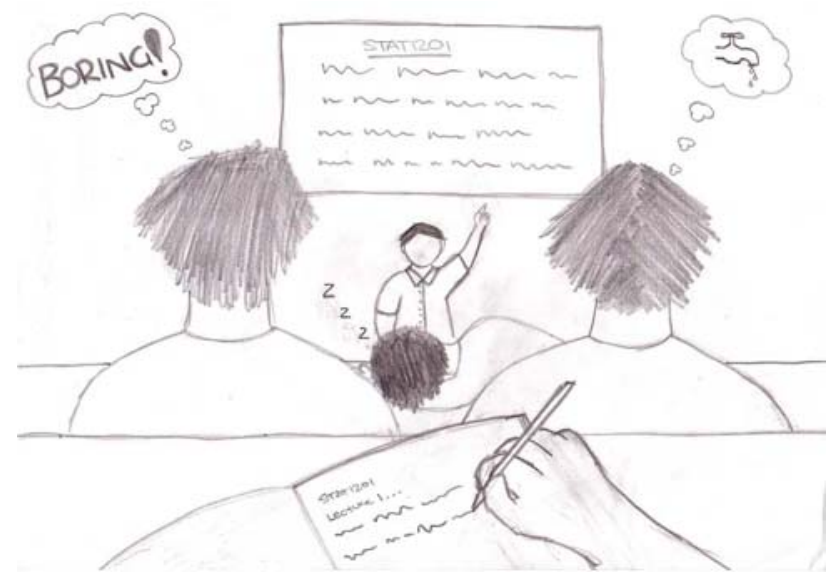

Figure 1. Example of category $\mathbf{A}$

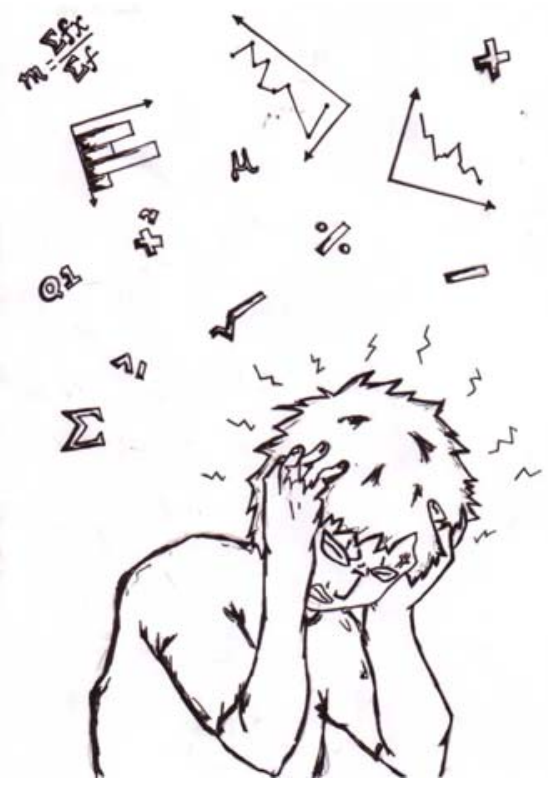

Figure 2. Example of category $\mathbf{B}$

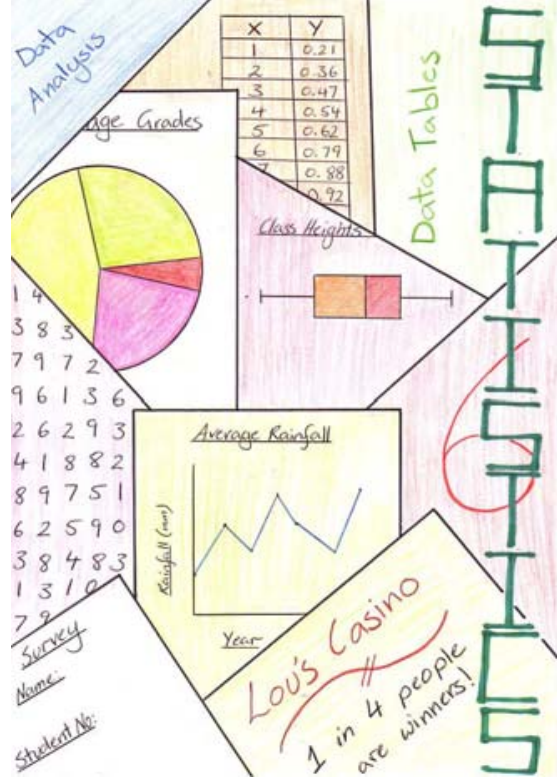

Figure 3. Example of category $\mathbf{C 1}$

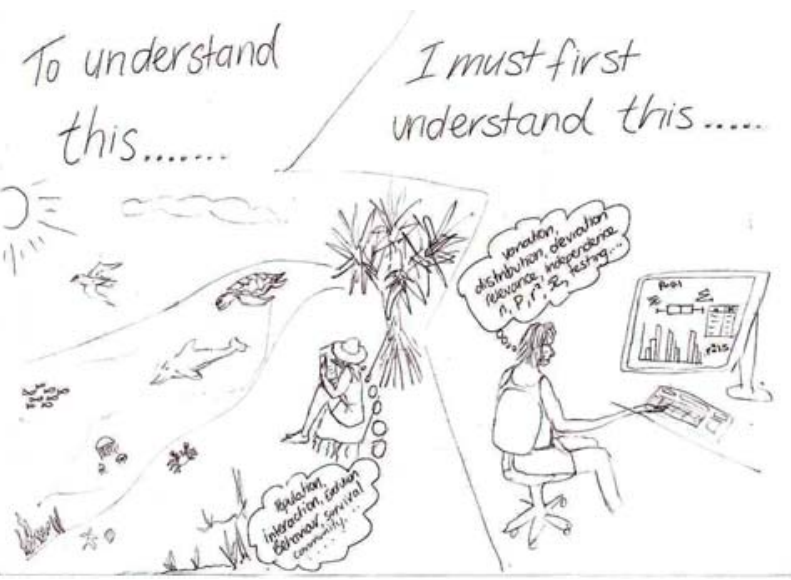

Figure 4. Example of category $\mathbf{C 2}$

maths \& stats a.. Way to make the world a litle, less exciting?

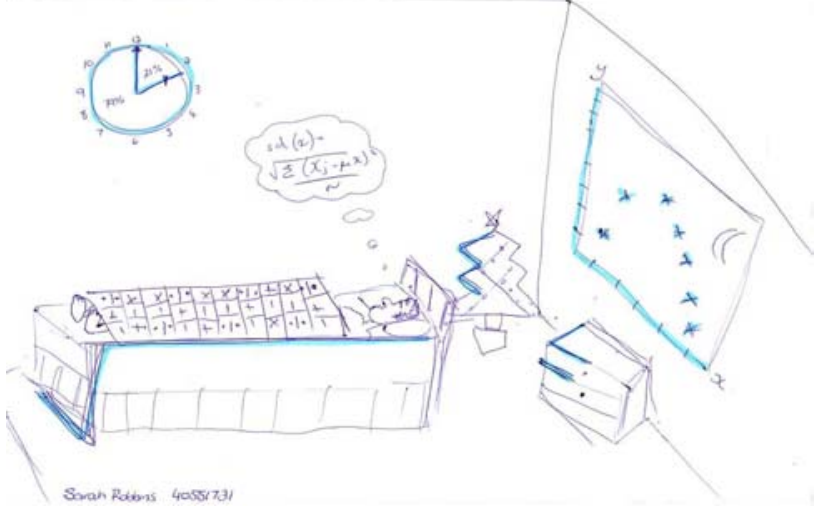

Figure 5. Example of category $\mathbf{G}$

Figure 6 shows the frequencies of these five categories identified in the 164 pictures. Category B dominates, perhaps reflecting the way in which statistics had been 
presented to these students in secondary school (as part of their mathematics courses). Category $\mathbf{G}$ was seen in 8 of the pictures.

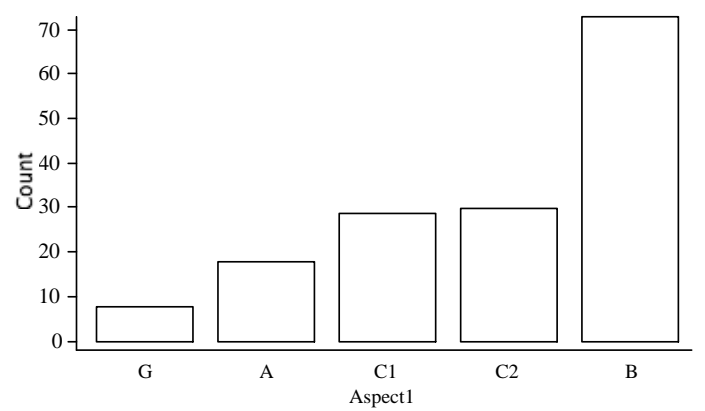

Figure 6. Frequencies of draft categories

\subsection{Reliability}

The five categories were tested by having an assistant use the operational definitions in Table 1 to reclassify the 164 pictures. The results of this reliability test are shown in Figure 7. Here 'Aspect1' is the category allocated by the authors while 'Aspect2' is the category allocated by the assistant.

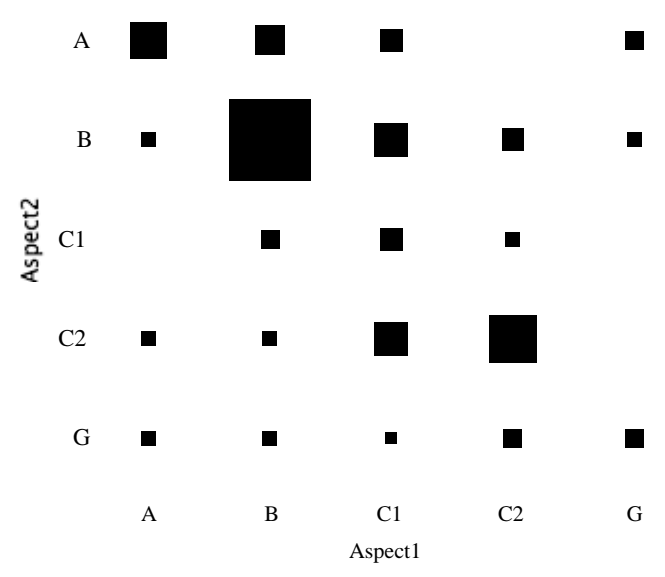

Figure 7. Reliability of draft categories

Categories A, B, and $\mathbf{C} 2$ had reasonable reliability. Of those classified as A by the authors, $67 \%$ were also classified as $\mathbf{A}$ by the assistant. This reliability statistic was $79 \%$ for $\mathbf{B}$ and $70 \%$ for $\mathbf{C} 2$. In contrast, of those classified as category $\mathbf{C 1}$ by the authors, only $14 \%$ were also classified as $\mathbf{C 1}$ by the assistant, with leakage primarily into categories B (31\%) and C2 (38\%). The value for category $\mathbf{G}$ was $38 \%$, but this is based on a small number of observations.

On analysing the assistant's explanations for her decisions, it was decided that the distinction between C1 and $\mathbf{C 2}$ was too difficult to reliably define. Both tried to capture the use of statistics as a means of modelling the world and these have been collapsed into a single category, C. Figure 8 shows the results of this simplification (and leaving out category $\mathbf{G}$ for clarity). Here 'RAspect1' is the revised category allocated by the authors while 'RAspect2' is the revised category allocated by the assistant. The reliability scores for $\mathbf{A}, \mathbf{B}$, and $\mathbf{C}$ are now $75 \%, 82 \%$, and $69 \%$, respectively.

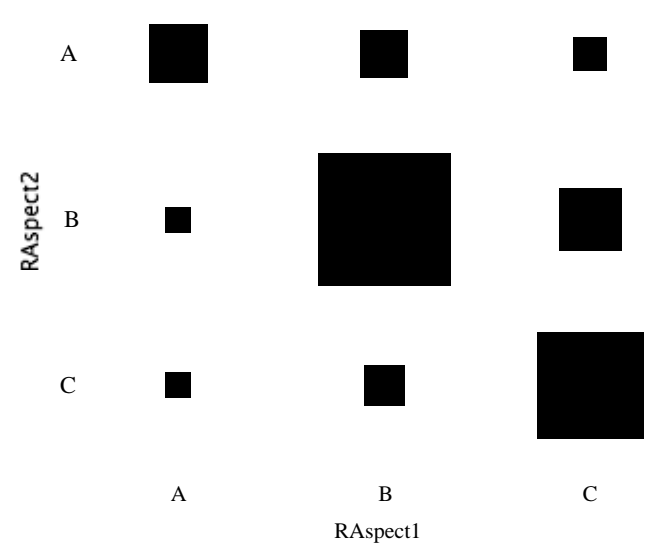

Figure 8. Reliability of combined categories

\subsection{Attitudes}

While the initial focus of our work was on levels of statistical understanding, data has also been collected on other dimensions of expression in the pictures. At the same time that the pictures were classified according to their statistical category, the two authors also independently assigned an attitudinal category to each picture. These we developed using the same process as before, with discussion around the first 50 pictures.

The attitudes in the pictures were classified as either $\mathbf{N}$ (negative), $\mathbf{P}$ (positive), or $\mathbf{Z}$ (zero, or neutral). The authors agreed that the majority of the pictures showed no strong attitude, with $77 \%$ classified as $\mathbf{Z}$.

As before, an assistant who was not involved in the development of these categories was asked to choose from the same attitudinal options. Figure 9 shows that she consistently classified as negative $(\mathbf{N})$ all the pictures classified as negative by the authors, and agreed with all but two (90\%) of the positive (P) classifications. However, she was more predisposed to identify a positive or negative attitude than the authors, agreeing with only $64 \%$ of the $\mathbf{Z}$ classifications.

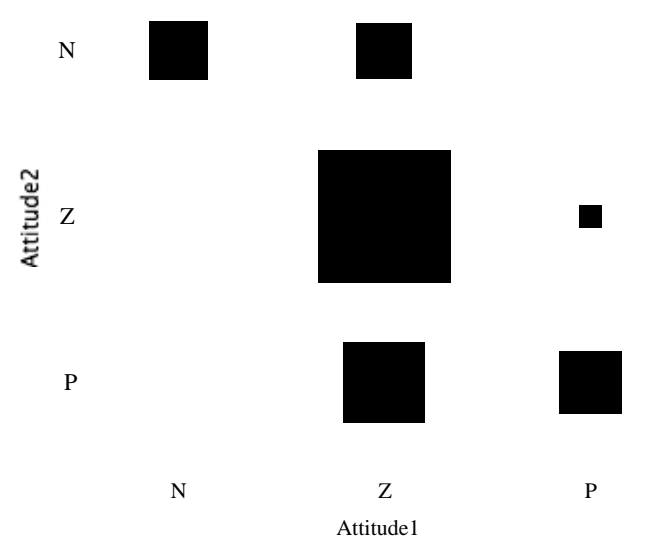

Figure 9. Reliability of attitudinal classification 
This suggests that the simple attitudinal classification may be rather subjective. The assistant wrote that

I've called them positive if they talk about the ability of stats to clarify/explain things in the natural world. I've given them a minus if they say stats is boring or difficult even when they later say that it will be useful.

Some of the positive aspect here relates to the category C2, in terms of utility, so it appears to have been difficult to separate the statistical and attitudinal dimensions. Further work needs to be done in this area to determine more precisely what is considered a "positive" or "negative" view towards statistics.

\subsection{Artistic Variety}

Although we have referred to the creation by a student as a "picture", the expression on the A4 sheet involved a wide range of means and artistic styles. The specification of the task asked students to "take a blank sheet of A4 paper and draw, write, paint, doodle, or whatever" suits them best to express their view on statistics. This freedom in the form of expression was given so that all students could comfortably contribute their views, regardless of artistic ability or confidence.

The artistic expression is naturally biased towards making pictures. For example, in category B students frequently drew examples of plots as statistical tools, but much less frequently wrote text like "mean" or "mode". Twelve students (7\%) submitted "pictures" that were purely text, as illustrated in Figure 10.

\begin{abstract}
I was not given the gift of artistic talent. I do however possess a brain that loves maths. It is this that will drive me through my degree. Statistics are what I believe to be the perfect maths for me. I simply love numbers. The possibilities with them are endless. Expressing and organising using numbers could never bore me. It blows my mind and I am fascinated with what is possible. When thinking about how I view statistics, I think positive thoughts. I cannot help it; numbers are just beautiful. The preface of 'Data Analysis' (Third Ed.) says that statistics is not a branch of mathematics. Maths deals with principles, rules, ideas and numbers. All of these are in statistics and are all the things I love. At the same time, statistics is special in its own way. It is not just a part of maths, but maths is a part of statistics. This study of variables, experiments, ideas and methods is fulfilling to the mind. It is logic, comprehensible and ingenious. The appreciation and promotion of statistics throughout our world is not at an adequate level. The hundreds of times I have told family and friends that I am doing a double major in maths and studying statistics have almost been amusing. The responses might as well have been the same; shock, surprise, disbelief. This needs to be changed. I want to promote that the love of maths and all things related is okay. Students should simply do what they love despite what the stereotypical thoughts on the topic are. This is my view on statistics at the start of the year. I hope it does not change; only develop positively.
\end{abstract}

Figure 10. Example of text "picture"

Within the constraints of their artistic ability, it is possible that the artistic means that a student chooses to express their view of statistics is related to their preferred learning style (Vermunt, 1996). For our current work we did not collect any data on preferred learning styles, so this potential link will have to wait for future research.

\section{Further Research}

Although based on very different methodology, there seems to be broad agreement between our A-B-C hierarchy and the hierarchical construct developed by Watson and Callingham (2003). Pictures in our A category show little appreciation of statistical methodology or utility, and as such present a rather idiosyncratic view of statistics. Pictures in the $\mathbf{B}$ category show that the student is aware of statistics as a collection of tools, corresponding to the middle levels of statistical literacy where the student can apply methods, either inconsistently or consistently. The $\mathbf{C}$ category incorporates some context and a sense of utility, reflecting a critical awareness of statistics.

However, while we have two hierarchies in broad agreement, the hierarchies are measuring different aspects of the student. For example, a student who draws a picture in the A category may well be able to critically apply statistical methods. Whereas Watson and Callingham (2003) based their hierarchy on a student's performance in a series of statistical tasks, the A4 picture provides only a snapshot of a student's statistical literacy and one which is intertwined with their attitudes towards statistics and towards studying statistics as a tertiary course. The next step in this research is to measure the students' statistical literacy using the Watson and Callingham tasks and compare the results with the pictures that the same students create.

While external data on statistical literacy was not available for these students, other data from the course assessment could be linked to the picture categories. An initial research question was whether there was an association between the picture of statistical beliefs and measures of subsequent performance in this course, such as marks on project work or examinations. If such associations did exist then this could suggest changes to the curriculum in order to address how particular beliefs are incorporated into teaching and learning. However, analysis of the data showed no significant associations. This may reflect the above comment that the pictures are measuring something different to statistical literacy. Again it would be useful to combine the picture categories with some standard measure of statistical literacy or a simple pre-test of statistical and mathematical knowledge.

In addition to the pictures, the course also involved the students keeping a reflective journal of their learning (Bulmer \& Rodd, 2005). This provides a dynamic view of student attitudes and affective responses over time, which could be used in conjunction with the picture classifications. The disadvantage of the reflective journals is that they are difficult to analyze, with around 170,000 words of free text written by this group of students. In contrast, the A4 pictures provide an efficient but rich insight into students beliefs and attitudes. 


\section{Acknowledgments}

Thanks to our assistant Rosanna Powell for her independent classification of the pictures. Thanks also to Ben Ong, Sarah Robbins, Caitlin Ryan, Kosma Smiechowski, and the other students for allowing us to use their pictures as illustrations.

\section{References}

Bulmer, M., \& Rodd, M. (2005). Technology for nurture in large undergraduate statistics classes. International Journal of Mathematical Education in Science \& Technology, 36(7). To appear.

Bulmer, M., \& Rolka, K. (2005). The "A4-Project” - Statistical world views expressed through pictures. In H. L. Chick \& J. L. Vincent (Eds.). Proceedings of the $29^{\text {th }}$ Conference of the International Group for the Psychology of Mathematics Education, Vol. 2, pp. 193-200. Melbourne: PME.

Cooney, T.J., \& Shealy, B.E. (1997). On understanding the structure of teachers' beliefs and their relationship to change. In E. Fennema \& B. S. Nelson (Eds.), Mathematics teachers in transition (pp. 87-110). Mahwah, NJ: Lawrence Erlbaum Associates.

Dionne, J.J. (1984). The perception of mathematics among elementary school teachers. In J. M. Moser (Ed.), Proceedings of the $6^{\text {th }}$ Annual Meeting of the North American Chapter of the International Group for the Psychology of Mathematics Education (pp. 223-228). Madison (WI): University of Wisconsin: PME-NA.

Ernest, P. (1991). The philosophy of mathematics education. Hampshire, UK: The Falmer Press.

Grigutsch, S., Raatz, U., \& Törner, G. (1997). Einstellungen gegenüber Mathematik bei Mathematiklehrern. Journal für Mathematikdidaktik, 19(1), 3-45.

Leder, G.C., Pehkonen, E., \& Törner, G. (Eds.) (2002). Beliefs: A hidden variable in mathematics education? Dordrecht, The Netherlands: Kluwer Academic Publishers.

Lloyd, G.M. (1999). Two teachers' conceptions of reform curriculum: Implications for mathematics teacher development. Journal of Mathematics Teacher Education, 2, 227-252.

National Council of Teachers of Mathematics (1989). Curriculum and evaluation standards for school mathematics. Reston, VA: Author.

Niederman, D., \& Boyum, D. (2003). What the numbers say: A field guide to mastering our numerical world. New York: Broadway Books.

Pajares, M.F. (1992). Teachers' beliefs and educational research: Cleaning up a messy construct. Review of Educational Research, 62(3), 307-332.

Schoenfeld, A.H. (1992). Learning to think mathematically: Problem solving, metacognition, and sense making in mathematics. In A. D. Grouws (Ed.), Handbook of research on mathematics teaching and learning (pp. 334-370). New York: Macmillan.

Steen, L.A. (Ed.) (1997). Why numbers count: Quantitative literacy for tomorrow's America. New York: College Entrance Examination Board.

Thompson, A.G. (1992). Teachers' beliefs and conceptions: A synthesis of the research. In A. D. Grouws (Ed.), Handbook of research on mathematics teaching and learning (pp. 127146). New York: Macmillan.

Törner, G. (2002). Mathematical beliefs - A search for a common ground: some theoretical considerations on structuring beliefs, some research questions, and some phenomenological observations. In G. C. Leder, E. Pehkonen \& G. Törner (Eds.), Beliefs: A hidden variable in mathematics education? (pp. 73-94). Dordrecht, The Netherlands: Kluwer Academic Publishers.

Törner, G., \& Grigutsch, S. (1994). Mathematische Weltbilder bei Studienanfängern - eine Erhebung. Journal für Mathematikdidaktik, 15(3/4), 211-252.

Vermunt, J.D. (1996). Metacognitive, cognitive and affective aspects of learning styles and strategies: A phenomenographic analysis. Higher Education, 31(1), 25-50.

Wallman, K.K. (1993). Enhancing statistical literacy: Enriching our society. Journal of the American Statistical Association, 88(421), 1-8.

Watson, J., \& Callingham, R. (2003). Statistical literacy: A complex hierarchical construct. Statistics Education Research Journal, 2(2), 3-46, http://fehps.une.edu.au/serj.

\section{Authors}

Rolka, Katrin, scientific assistant, Department of Mathematics, University of Duisburg-Essen, Forsthausweg 2, 47057 Duisburg, Germany Email: rolka@math.uni-duisburg.de

Bulmer, Michael, senior lecturer, Department of Mathematics, University of Queensland, Australia Email: $\underline{\text { m.bulmer@uq.edu.au }}$ 